\title{
A globalização e os desafios para os sistemas nacionais: agenda internacional e práticas educacionais nacionais
}

CARLOS ROBERTO JAMIL CURY

\author{
INTRODUÇÃO
}

Em texto instigante publicado no Brasil em 1992, Norberto Bobbio refletia sobre a Era dos Direitos. Respondia ele a um entrevistador que o perquiria sobre as características do tempo presente e sua relação com o futuro da humanidade. Bobbio responde assinalando uma tensão existente de cuja atualidade não se pode duvidar: de um lado, as sombras trazidas "pelo aumento cada vez mais rápido e até agora incontrolado da degradação do ambiente, o aumento cada vez mais rápido, incontrolado e insensato do poder destrutivo dos armamentos e, de outro, as luzes acenadas pelo reconhecimento dos direitos do homem" (p. 49). Para esse lúcido pensador, na esteira de Kant, os direitos humanos seriam um indicador do "progresso moral da humanidade" que teria na "vertiginosa corrida armamentista um freio" na via desse progresso, freio manipulado por forças políticas imobilistas.

Em outra chave, no Manifesto, Karl Marx também apontava, na burguesia de então, essa tensão de luzes e sombras. O termo burguesia, utilizado por Marx em texto emblemático da Era Moderna, pode muito bem, em nossa atualidade, ser substituído pelo termo globalização. De um lado, a aproximação entre povos, o avanço tecnológico e o aumento da produtividade e, de outro, a exploração social aprofundada no interior das nações e dominação entre nações pelas barreiras à circulação do trabalho. Poder-se-ia, para os dias de hoje, assinalar a busca de uma escala planetária mediada pela tecnologia, a celeridade da informação e da comunicação, a nanotecnologia e a biotecnologia. Concomitantemente, convive-se com a produção de riscos que ameaçam o planeta, como a poluição, os agrotóxicos, o aquecimento global, o comércio, até mesmo o legalizado, das armas próprias das práticas militares, o tráfico ilegal de armas e as drogas.

Por seu turno, Zygmunt Bauman (2006), sociólogo que em vários dos seus livros tece reflexões sobre as consequências humanas da modernização em escala global, também coloca a pobreza como item importante da pauta das discussões contemporâneas. Num livro denominado significativamente Vidas desperdiçadas, aproxima a produção do lixo stricto sensu, as montanhas de dejetos des- 
cartados por sociedades que não conseguem consumir tudo o que produzem, à simultânea produção dos seres humanos refugados, os 'excessivos', os 'redundantes'.

Refere-se assim aos que são esquecidos, aos indesejados, às massas de anônimos subempregados ou mendigos, aos pobres, aos excluídos do progresso econômico.

Os refugiados, os deslocados, as pessoas em busca de asilo, os migrantes, os "sans papiers", constituem o refugo da globalização. Mas não, nos nossos tempos, o único lixo produzido em escala crescente. Há também o lixo "tradicional" da indústria, que acompanhou desde o início a produção moderna. Sua remoção apresenta problemas não menos formidáveis que a do refugo humano, e de fato ainda mais aterrorizantes - e pelas mesmíssimas razões: o progresso econômico que se espalha pelos mais remotos recantos de nosso planeta "abarrotado", esmagando em seu caminho todas as formas de vida remanescentes que se apresentem como alternativa à sociedade de consumo. (BAUMAN, 2006, p.76).

Lixo urbano e lixo humano: corolários dos processos acelerados de uma globalização desigual, assimétrica e antiecológica.

Mais recentemente, o papa Francisco lançou a Encíclica Laudato Si: sobre o cuidado da Casa Comum (BERGOGLIO, 2015), que trata, de modo abrangente, da questão ambiental em nosso tempo, sinalizando aspectos éticos relativos à preservação ambiental, redefinindo relações de poder. Segundo essa Encíclica,

Torna-se difícil parar e retomar a profundidade da vida. Se a arquitetura reflete o espírito duma época, as megaestruturas e as casas em série expressam o espírito da técnica globalizada, onde a permanente novidade dos produtos se une a um tédio enfadonho. Não nos resignemos a isto e nem renunciemos a perguntar pelos fins e pelo sentido de tudo. Caso contrário legitimaremos o estado de fato e precisaremos de mais sucedâneos para suportar o vazio. (p. 113)

Torna-se imperativo lembrar-se da obra do artista plástico brasileiro, Vick Muniz, que, servindo-se de materiais descartáveis, aponta para o desperdício de vidas humanas e do meio ambiente como subprodutos de uma globalização sem freios.

Este quadro, que aproxima vários pensadores e artistas distantes no tempo e em suas concepções, embora próximos na acuidade analítica, tem um fundamento real no processo hoje vivenciado pelos países e pelas pessoas, envolvendo uma intensificação inaudita das trocas comerciais, da produção de bens e serviços a partir de múltiplos polos econômicos; da aceleração das comunicações e informações em tempo real; das trocas culturais. Costuma-se, por vezes, denominar esse processo Aldeia Global, cujo âmago teria como base uma 'sociedade do co- 
nhecimento' de tal modo que a circulação dos conhecimentos não ficaria fora de nenhum aspecto da existência social, aí compreendida a educação. Tal processo real também pode ser flagrado na tendência homogeneizadora que caracteriza a metropolização urbana em escala mundial, bem como no caráter frágil dessas metrópoles, sobretudo nos seus espaços periféricos, exemplos contundentes da acentuação das disparidades internas. De qualquer modo, a tensão permanece entre dinâmicas tendencialmente homogeneizadoras vistas em fluxos de capitais com as práticas e os sentidos que os acompanham, tanto quanto os fluxos migratórios quanto a fragmentação, características das periferias urbanas, isoladas e fragmentadas.

Este quadro contraditório e perverso se nutre, na expressão de Dardot e Laval (2016) de uma nova razão do mundo.

\section{GLOBALIZAÇÃO}

Essa raz̃ão engendra e supõe um sistema de produção de relações econômicas que, forçados pela concorrência mundial, os Estados buscam trazer para si vantagens competitivas. Desse modo, postula-se uma maior relação entre o sistema de produção e as necessidades exigidas por ele. Boa parte de tais exigências passa a ser solicitada da educação porque, afinal, uma 'sociedade do conhecimento', calcada na competição, exige conhecimentos de base, competências e habilidades próprias da realidade existente.

É certo que a educação escolar se expandiu no mundo todo, generalizando o ensino fundamental e, em muitos países, o ensino médio. Essa realidade de acesso alargado também se deu no Brasil. Se a atratividade em disputa entre os países é consequência da globalização e se a generalização da escola se deu, ainda que diferencialmente, entre os países, então a busca de modelos de comparação entre os sistemas nacionais é uma consequência. E, para tanto, seriam necessárias referências, tais como avaliações em larga escala, que dessem sustentação à comparabilidade na denominada 'sociedade do conhecimento' dentro de cada país e entre países.

Assim, duas realidades, objeto deste Seminário, se cruzam: a da educação escolar e a presença de organismos multilaterais como o Banco Mundial, a Organização para a Cooperação e Desenvolvimento Econômico (OCDE), a Organização das Nações Unidas para a Educação e a Ciência (UNESCO) cujas diretrizes e orientações tornam-se parâmetros de referência da qualidade dos co- 
nhecimentos, habilidades e competências. Esses organismos passaram por uma mudança interna havida no final dos anos 80, pela qual os economistas, e não os juristas, passaram a ser grupo hegemônico dentro deles. ${ }^{1}$

O Banco Mundial, criado em 1945, com a finalidade de auxiliar a reconstrução dos países devastados pela $2^{\text {a }}$ Guerra, reorientou essa finalidade para a ajuda financeira por empréstimos aos países pobres em dificuldades no seu desenvolvimento. Em seu relatório "Uma perspectiva de estudo a longo prazo" de 1989, propõe um maior protagonismo para o sistema contratual de mercado articulado a uma governança caracterizada, de um lado, pela eficiência e, de outro, pela accountability (prestação de contas) ${ }^{2}$.

A OCDE, existente desde os anos 60, com sede em Paris, desde os anos 90 , vem apoiando formas de avaliação educacional que buscam influenciar não só o Brasil mas muitos outros países. De acordo com a página oficial da OECD (www.oecd.org), a missão dessa organização é promover, no mundo, políticas que façam crescer e desenvolver a economia de mercado com vista ao bem estar das populações.

Para tais organismos, o setor público, para ajustar-se aos novos tempos, deveria revestir-se de um novo modus operandi caracterizado pelo melhor design do setor privado em termos de gestão, revendo custos e apoiando a severidade nos gastos com vistas ao ajuste fiscal. Trata-se do denominado new public management (NPM), pelo qual o setor público adapta-se internamente aos novos tempos por meio de uma reengenharia interna que supõe a diminuição do tamanho do Estado, o aumento da eficiência e a publicização de seus atos. Tanto a OCDE quanto o Banco Mundial apelam para pessoas, no governo ou fora dele, dispostas a reformar os serviços públicos a fim de que abracem um modo de ofertá-los que estabeleça objetivos de desempenho eficaz e se coloca como parceiros nessa tarefa. Ou, como dizem Dardot e Laval (2016),

O neoliberalismo antes de ser uma ideologia ou uma política econômica, é em primeiro lugar e fundamentalmente uma 'racionalidade' e, como tal, tende a estruturar e organizar não apenas a ação dos governantes, mas até a própria conduta dos governados (p. 17).

O conceito próprio de governança que anima tais organismos se refere à capacidade do Estado de pôr em ação as políticas públicas orientadas por parcerias entre o setor público e privado, como, por exemplo, Organizações Não-Governamentais (ONG), diminuindo custos, estimulando a busca de resultados

\footnotetext{
1 Cf. Almeida, 2008; 2009

2 Cf. Meyer, Tröhler, Labaree e Hutt (2014).

18 - RBPAE - v. 33, n. 1, p. 015 - 034, jan./abr. 2017
} 
positivos e expondo seus resultados de modo transparente, prestando contas à sociedade $^{3}$. A partir dos anos 80 a aceleração da concorrência mercantil, generalizando-a para todas as esferas de governo, da vida social e do próprio sujeito, ganharia a denominação de neoliberalismo.

Continuando com Dardot e Laval (2016), "O neoliberalismo pode ser definido como o conjunto de discursos, práticas e dispositivos que determinam um novo modo de governo dos homens segundo o princípio universal da concorrência" (p. 17).

E o tema da accountability, ligado a desempenho e resultados, representa uma significativa mudança no âmbito das políticas públicas, constituindo o mote para uma presença desses organismos no âmbito nacional, implicando um balanço entre nacional e internacional. ${ }^{4}$

Por se tratar de organismos internacionais, eles apresentam orientações e diretrizes. Quando os países aceitam empréstimos do BM ou as orientações gerais da OCDE, então acatam todo um conjunto de medidas de ajuste de contas com planejamento, medidas e, sobretudo, avaliações, das quais decorrem uma classificação, um ranking com as distintas posições de cada país.

Ao contrário de certa percepção imediata, e de certa ideia demasiado simples, de que os mercados conquistaram a partir de fora os Estados e ditam a política que estes devem seguir, foram antes os Estados, e os mais poderosos em primeiro lugar, que introduziram e universalizaram na economia, na sociedade e até neles próprios a lógica da concorrência e o modelo de empresa. ... Mais uma vez, comprovamos as grandes análises de Marx, Weber ou Polanyi segundo os quais o mercado moderno não atua sozinho: ele sempre foi amparado pelo Estado. (Dardot e Laval, 2016, p. 19)

Como diz Ruano-Borbalan (2011),

Em todos os casos - e é o que se passa, realmente, tanto nos Estados Unidos quanto na Europa - o Estado (ou as coletividades territoriais) continua sendo o principal ator: ocupa-se da gestão e administração (diretamente ou não), visto que estabelece os marcos legislativos, institucionais e curriculares, além de organizar o conjunto dos sistemas de apoio, parcerias e abertura atores privados (p. 444).

3 O conceito de governança é polissêmico, ora opondo -se a uma administração estatal muito burocratizada mas sem descaracterizar o papel do Estado, ora propondo, de fato, um Estado mínimo melhor administrável. Para uma descrição analítica de novas maneiras de se fazer políticas pública, cf. Draibe, 1993.

4 Também o conceito de accountability é polissêmico, sendo o que os difere o sentido da presença do sujeito apenas parte interessada enquanto cliente, "empresário de si" ou como partícipe dos destinos da comunidade. Segundo Dardot e Laval (2016), "A reestruturação neoliberal transforma os cidadãos em consumidores de serviços que nunca têm em vista nada mais além de sua satisfação egoísta, o que faz que sejam tratados como tais por procedimentos de vigilância, restrição, punição e 'responsabilização"'. p. 320). Cf. também, p. 350 e 353. 
Nesse sentido, tais organismos se vêm impondo tendencialmente como autoridade educacional internacional que, por meio de um processo de avaliação, concorre com outras formas de autoridade educacional nacional. É certo que, em um país federativo, além do polo nacional de poder, há outros polos subnacionais, o que torna mais complexa a definição top down de políticas educacionais. Essa autoridade busca legitimar-se por meio de um processo de avaliação que vem acompanhado de conceitos, referências e especialmente medidas, classificações e estatísticas para avaliar resultados de políticas educacionais. $\mathrm{Na}$ crítica de Dardor e Laval (2016)

A "avaliação" tornou-se o primeiro meio de orientar a conduta pelo estímulo ao "bom desempenho" individual. Ela pode ser definida como uma relação de poder exercida por superiores hierárquicos encarregados da expertise dos resultados, uma relação cujo efeito é uma subjetivação contábil dos avaliados. (p. 351)

Boa parte dessas avaliações ganha grande espaço na mídia, o que aumenta a circulação delas. Como bem posto por Dardot e Laval (2016)

O neoliberalismo é um sistema de normas que hoje estão profundamente inscritas nas práticas governamentais, nas políticas institucionais, nos estilos gerenciais. (...) Ele estende a lógica do mercado muito além das fronteiras estritas do mercado, em especial, produzindo uma subjetividade "contábil" pela criação da concorrência sistemática entre os indivíduos. Pense-se em particular na generalização dos métodos de avaliação no ensino público oriundos da empresa. (p. 30). ${ }^{5}$

Um exemplo bem claro desta tendência no campo da educação é o programa Race to the Top em cuja página (http://www2.ed.gov/programs/racetothetop/index.html) podem-se ler seus objetivos:

A adoção de padrões e de avaliação que preparem os estudantes para serem bem sucedidos na escola, no lugar de trabalho e poderem competir na economia global; [...] - a construção de um sistema de dados que mensurem o crescimento e o sucesso dos estudantes e informe os docentes e gestores de como eles podem melhorar a instrução; [...] - o recrutamento, o desenvolvimento, a recompensa e a retenção de professores e gestores, especialmente onde deles mais se necessita; [...] - superando o baixo desempenho encontrado em escolas com tal realidade (livre tradução nossa).

Os estudantes devem dominar as 'habilidades' (skills) por meio das quais deverão participar de modo produtivo em sua inserção profissional no sistema de mercado dentro da 'nova razão do mundo'.

Da divulgação dos resultados, do decantado prestígio dessas organizações, pode-se dizer que acaba havendo uma espécie de monitoramento indireto

5 Cf. Laval, 2004.

20 - RBPAE - v. 33, n. 1, p. 015 - 034, jan./abr. 2017 
das políticas educacionais nos países e a busca de, lentamente, introduzir nos próprios estudantes e na população os ditames desta 'racionalidade'. Como assinalam Dardot e Laval (2016):

\begin{abstract}
O neoliberalismo não destrói apenas regras, instituições, direitos. Ele também produz certos tipos de relações sociais, certas maneiras de viver, certas subjetividades. Em outras palavras, com o neoliberalismo, o que está em jogo é nada mais nada menos que a forma de nossa existência, isto é, a forma como somos levados a nos comportar, a nos relacionar com os outros e com nós mesmos. O neoliberalismo define certa norma de vida nas sociedades ocidentais e, para além dela, em todas as sociedades que as seguem no caminho da 'modernidade' (p. 16).
\end{abstract}

É nessa orientação manifesta e profunda que, segundo estes autores, essa 'nova razão do mundo' torna-se normativa de que o modus vivendi seja o da competição. O próprio indivíduo acaba por se comportar como se fora uma empresa, uma empresa de si próprio.

Por outro lado, a recepção a essas orientações e diretrizes se configura dentro do provérbio escolástico 'tudo o que é recebido, é recebido segundo a forma do recipiente'. Não é por outra razão que tais realidades são tensas e contraditórias com os valores proclamados e assinalados em Constituições e legislação e acabam por desafiar os governos nacionais e a própria cidadania na reversão desses processos em vista de respostas também para os direitos sociais conquistados e positivados, para os direitos humanos celebrados e exigidos especialmente por aqueles grupos que anseiam por uma participação nos destinos de seu país.

\title{
POLÍTICAS DE AVALIAÇÃO NO BRASIL
}

O Brasil é partícipe como membro signatário do Banco Mundial. A integração do Brasil em Comitês da OCDE como participante ou observador regular tem avançado rapidamente. Tem status de participante pleno em órgãos oficiais da OCDE, participando em diversos programas sobre educação, incluindo o Programme for International Student Assessment (PISA), ou seja, Programa Internacional de Avaliação de Alunos, sendo observador regular em Comitês ou Grupos de Trabalho e seus órgãos subordinados. O País é particularmente ativo do Comitê de Competição e do Comitê de Governança Pública, para os quais envia delegados de alto nível.

As políticas de avaliação em educação oscilam, em geral, entre dois paradigmas. Um é mais tradicional e de natureza interna às instituições, mediante provas e exames e, mais recentemente, comporta a avaliação da identidade institucional do estabelecimento mediante autoavaliação. O outro, de natureza externa às instituições e aos estudantes, tem uma tônica de recenticidade. 
Entretanto, o que se nota é que o segundo vem tornando-se hegemônico, enquanto o primeiro busca recuperar seu lugar redefinindo sua amplitude.

Datam dos anos 90 as políticas de avaliação de desempenho do ensino, regidas por avaliação externa, sistemática e padronizada.

Nos anos 90, desenvolveu-se no mundo inteiro um paradigma do ensino e que veio a ser chamado de cultura da avaliação. Tal paradigma faz parte das denominadas agendas nacionais de avaliação bafejadas pela agenda internacional sugerida por organismos multilaterais.

Tais agendas entronizaram reformas educacionais que, de um lado, propiciaram maior acesso às vagas e, de outro lado, estimularam processos de avaliação do rendimento e do desempenho das instituições e dos estudantes.

Segundo todos os documentos relativos à avaliação, ela teria a função de ser um instrumentos de legitimação de um processo de ensino/aprendizagem que propiciasse maior eficácia nos resultados de desempenho da educação.

Esta avaliação externa veio a se tornar hegemônica passando a ser, por assim dizer, o instrumento de regulação e de estratégia da política educacional. ${ }^{6}$

O outro paradigma, ainda que recessivo, é o da avaliação interna que sempre respondeu por um sistema de controle promovido interna corporis quanto aos docentes e constituído de deveres e provas finais quanto aos estudantes, sendo mais diversificado no ensino superior. Mais recentemente, este paradigma, em especial na educação superior, ganhou certo espaço tendo como objetivo valorizar a identidade e a diversidade institucionais as quais deveriam ser consideradas no conjunto da avaliação.

Sob estes dois paradigmas, tensos entre si, um sob influxo internacional e o outro como componente nacional, atualmente são processos de oposição ou de negociação, inclusive fazendo parte da legislação nacional.

\section{BREVE MEMÓRIA HISTÓRICA NO BRASIL}

Em 1936, o Plano Nacional de Educação, levado adiante pelo Ministério da Educação e Saúde Pública e pelo Conselho Nacional de Educação, após extensa consulta à comunidade científica de então, propunha para os formandos o denominado exame de Estado. Por ele, os formandos só poderiam exercer sua profissão se passassem neste exame. Com a instalação do Estado Novo, este plano deixou de ser aprovado. O que temos hoje de um exame que se aproxima àquele dispositivo é o exame da Ordem dos Advogado do Brasil (OAB).

$6 \quad$ Cf. Werle, 2014 e Schneider, 2013. 
Na década de 60, o movimento estudantil de então e os estudos do prof. Álvaro Vieira Pinto, do Instituto Superior de Estudos Brasileiros (ISEB), indicavam a necessidade de uma avaliação do ensino superior em vista da ampliação do acesso e do conteúdo de seus programas que deveriam refletir criticamente sobre a realidade nacional.

Já entre os anos 80 e 90, vários ensaios de avaliação vieram à luz do dia, mas cuja efetivação ficou nos documentos que os registraram.

Assim, o Programa de Avaliação da Reforma Universitária (PARU), a ser executado pela CAPES, foi proposto em 1982/83, a fim de avaliar a lei n. $5.540 / 68$ em torno das reais condições nas quais se realizavam as atividades de produção e disseminação do conhecimento. Bem elaborado, quase consensual, tinha uma vasta extensão propositiva e se situava em um contexto de grande movimentação sociopolítica. Talvez, por isso, não tenha passado de alguns relatórios.

No caso da Educação Superior, havia a avaliação da pós-graduação pela CAPES, desde os anos 70. Após o advento da denominada Nova República, a Associação Nacional de Docentes do Ensino Superior (ANDES) se bateu por uma avaliação, a ser levada adiante pelos pares e que enfatizava a dimensão do dever-ser. Concomitante a isto e quase que como resposta a tais demandas, o governo Sarney, em 1985, cria a Comissão Nacional da Reforma do Ensino Superior. Ela elaborou um diagnóstico bastante variado da situação do ensino superior de então e apontou para a necessidade de desenvolvimento de sistemas de avaliação do ensino superior, objetivando uma otimização de recursos humanos e financeiros, um diagnóstico preciso da universidades confrontado com as críticas feitas ao aparato universitário.

Havia uma série de propostas em vista de uma legitimação deste nível de ensino e para viabilizá-las foi criado, em 1986, o Grupo Executivo da Reforma da Educação Superior (GERES). O GERES, grupo menor, defendeu uma avaliação de desempenho (externa), subordinada a um controle finalístico das instituições pelo Estado.

Face à polêmica suscitada entre o GERES e a ANDES, surgiram vários documentos sobre o assunto, entre os quais cumpre assinalar os emitidos pela Sociedade Brasileira para Progresso da Ciência (SBPC), Conselho Técnico Científico (CTC /CAPES), Conselho de Reitores das Universidades Brasileiras (CRUB), Conselho de Reitores das Universidades de São Paulo (CRUESP) nos quais a avaliação é reconhecida como legítima e necessária, mas evitando qualquer tipo de punição ou recompensa.

Nos anos 90, sob o governo Collor, houve a divulgação da chamada lista dos improdutivos das Universidades, embora tenha tido como foco a Universidade São Paulo. Esta lista, em base pouco fidedigna, elencava os docentes com pou- 
ca publicação em jornais de grande circulação. Contudo, a disseminação da lista politizou de tal modo o debate sobre a universidade que obrigou a comunidade científica se posicionar em relação a um processo mais sistemático de avaliação. Não faltou quem visse na lista dos improdutivos um sentido de avaliação que servisse de álibi para uma omissão do poder público quanto ao financiamento das IES públicas ou que ocultasse algum projeto de privatização.

Após a defenestração de Collor e o seu projeto de desmonte do Estado, o governo Itamar Franco, uma vez sensibilizada a comunidade científica, via SBPC, CRUB e o próprio MEC, instituiu o Programa de Avaliação Institucional das Universidades Brasileiras (PAIUB). Mediante uma radiografia de vários quesitos e por meio de um processo de avaliação interna por pares, o PAIUB buscava um sistema de avaliação que permitisse o autorreconhecimento crítico da situação da universidade, sua identidade própria, a superação dos problemas detectados e a prestação de contas à sociedade e ao Estado do desempenho e dos resultados da Universidade.

Paralelamente a este processo, tramitavam no Congresso projetos de lei de diretrizes e bases da educação nacional pondo dois projetos em disputa. Pode-se dizer que o mais antigo, proposto em 1988, era mais analítico e de certo modo explicitava um papel mais ativo do Estado na oferta da educação pública e no controle das redes privadas. O outro projeto, bem mais sintético, continha uma larga flexibilidade no interior do ordenamento legal. ${ }^{7}$

Com a extinção do Conselho Federal de Educação em 1994, com a posse de Fernando Henrique Cardoso em 1995 há a sanção da lei n. 9.131/95 que antecipa em muitos quesitos a própria LDB. Por ela há a (re)criação do Conselho Nacional de Educação e a introdução de um sistema de avaliação externa, periódica e sistêmica tanto das instituições como de seus cursos, abrangendo a educação superior. O Exame Nacional de Cursos (Provão), disposto nesta lei foi regulamentado pelo Decreto n. 2.026/96, estabelecendo uma avaliação do rendimento dos cursos o qual serviria como um indicador de planejamento. Este sistema serviu para classificar (ranquear) as instituições e cursos pelas letras de A à E. Mais tarde, pelo Decreto n. 3.860/2001 exige-se um Questionário socioeconômico acompanhado da avaliação das condições de oferta (por exigência da lei n. 9.394/96) e avaliação das condições de ensino (por exigência da lei n. 9.394/96).

Este Exame Nacional do Cursos estabelecia um modus operandi em que se destacava a avaliação externa do rendimento e desempenho dos estudantes, sem que as outras avaliações ganhassem igual prestígio. $\mathrm{O}$ exame era obrigatório para os estudantes e de sua realização dependia o recebimento do diploma.

$7 \quad$ Cf. Saviani, 1997.

24 - RBPAE - v. 33, n. 1, p. 015 - 034, jan./abr. 2017 
A lei n. 9.394/96, a das diretrizes e bases da educação nacional (LDB), consagrou em seu corpo legal, os pilares da flexibilidade e da avaliação. E isto se deu de tal modo que, pela flexibilidade, não só houve uma grande expansão diferenciada da rede privada, como também a organização pedagógica ficou bem autônoma e diversa. Por sua vez, a avaliação ganhou uma dimensão jamais vista no ordenamento educacional (vide art. $9^{\circ}$, VI, VIII e IX e art. 87, IV da LDB) de tal modo que se tornou um sistema nacional de avaliação do rendimento escolar abrangendo a educação básica e a educação superior. E esta avaliação se caracteriza por ser externa, sistemática e sistêmica incidindo sobre o rendimento, as instituições e os cursos agora também da educação básica. Nesse sentido, ela confirmou os pressupostos da lei n. 9.131/95 e os ampliou para o conjunto da educação escolar brasileira. É também verdade que o texto legal não deixou de apontar a qualidade e, identificadas lacunas e insuficiências, caberia ao poder público tomar medidas necessárias para a superação das mesmas.

Mas qual seria o referencial desta qualidade?

\section{GESTORES DA EDUCAÇÃO NACIONAL E MEDIADORES DA PRESENÇA INTERNACIONAL}

Aqui importa trazer uma hipótese de estudo relativa à constituição dos gestores da educação nacional deste período. Contudo, pode-se citar antes o trecho de uma análise do papel da OECD e governos nacionais da lavra de Meyer (2014a):

No passado, a OCDE ganhou confiança e influência devido a uma posição de
neutralidade, limitando-se a prover dados e análises, além do compromisso na abs-
tenção de interferência nas políticas internas e nas práticas dos governos membros.
Cada vez mais, esse sábio compromisso com a neutralidade e a abstenção de inter-
ferência, está abrindo caminho para um deslocamento de limites entre análises e o
envolvimento da OCDE com reformas na base. Um caso específico é o tratado de
cooperação de 2008 com o governo mexicano, intitulado "Calidad Educativa/ Qua-
lity Education" descrita pela OCDE como "uma iniciativa conjunta da Diretoria da
Educação da OCDE e o Ministério da Educação do México, Secretaría de Educa-
ción Pública - SEP, no afã da melhoria da qualidade da educação no México". [...].
Esse acordo teve a assistência da OCDE para o Governo Mexicano na reforma
educacional em áreas como gestão escolar e participação social, recrutamento, sele-
ção, formação, treinamento, incentivo, estímulos e avaliação do professorado. (p. 7)

Alguns gestores e seus assessores, no Brasil, importantes e influentes, têm algo que os caracteriza: a circulação internacional, sendo que boa parte deles esteve presente em organismos multilaterais com relação a projetos de educação. 
Os conhecimentos obtidos nesses organismos condicionou sua atuação, nos governos ou fora deles. à luz dos pressupostos dessas agências.

Tais gestores e assessores podem ser caracterizados como think tanks ${ }^{8}$ na medida em que ao se traduzirem como grupo de interesses comuns difundem conhecimentos que visam a mudanças nas políticas públicas, revendo políticas consideradas anacrônicas para uma sociedade complexa e em movimento. ${ }^{9}$ Uns mantêm Organizações não Governamentais, outros atuam em secretarias governamentais e, de modo geral, têm grande acesso à grande mídia. Ou nos termos de Dardot e Laval (2016)

\begin{abstract}
Esses “intelectuais orgânicos" do neoliberalismo, afirmando-se ora de direita, ora de esquerda, ou sucessivamente um e outro, tiveram um papel-chave na naturalização dessas práticas, em sua neutralização ideológica e, por fim, em sua implantação prática. Células de pesquisa, inúmeros colóquios, amplas operações de formação de quadros de função pública, produção e difusão maciça de um léxico homogêneo, verdadeira língua franca das elites modernizadoras, acabaram por impor o discurso ortodoxo da gestão. Mas não nos enganemos: as políticas neoliberais não foram implantadas em nome da "religião do mercado", mas em nome de imperativos técnicos de gestão, em nome da eficácia, ou até mesmo da "democratização" dos sistemas de ação pública. (p. 231)
\end{abstract}

O primeiro deles foi o (ex) Ministro da Educação do governo FHC: Paulo Renato Souza, economista com passagem pela CEPAL (Divisão de Desenvolvimento Econômico), Organização dos Estados Americanos (OEA) e pelo Banco Interamericano de Desenvolvimento (BID). ${ }^{10}$

Outro, Luiz Carlos Bresser Pereira, idealizador da Reforma do Estado, docente da Fundação Getúlio Vargas, tem formação jurídica e administrativa, com passagens pelos Estados Unidos, Inglaterra e França, interessando-se pelo estudo de teorias relativas à administração pública e privada. Hoje é crítico do neoliberalismo pelas consequências que veio acarretando aos mais vulneráveis.

Claudio Moura Castro, outro deles, é economista, ex-funcionário tanto do Banco Mundial quanto do BID, e membro importante da intelligentsia que assessorou o MEC em vários campos da educação, inclusive na relação entre Ensino Médio e Educação Profissional durante o governo Fernando Henrique

8 Os think tanks podem ser definidos como grupos de interesses institucionalizados que, por meio de consultorias, geralmente pagas, fornecem estudos e análises sobre determinadas matérias. Com elas os think tanks visam alterar situações existentes tidas como pouco eficientes, porque comumente seriam tratadas por grupos ou pessoas sem a adequada fundamentação.

9 De acordo com McGann (2016), o Brasil conta com 89 think tanks, ocupando a $12^{\mathrm{a}}$ posição no mundo. Um dos lugares mais considerados no Brasil é a Fundação Getúlio Vargas (FGV). Para maiores informações, cf. Melo, 2012 e Moreno, 2013

10 Antes de seu prematuro falecimento, ele escreveu um livro muito significativo. Cf. Souza, 2005 
Cardoso. Muitos projetos financiados para a educação brasileira se tornaram uma via importante pela qual as propostas da OCDE e do Banco Mundial tomaram corpo no Brasil.

Ainda, João Batista Araújo e Oliveira, psicólogo (ex-funcionário do Banco Mundial e da OIT), como Moura Castro, apoiou, como consultor, os programas levados adiante por Paulo Renato Souza. ${ }^{11}$

Finalmente, Simon Schwartzman, sociólogo, sempre esteve envolvido em projetos e publicações relativos à educação, foi consultor do Banco Mundial no setor educacional e de ciência e tecnologia. Com grande experiência internacional, passou pelo Chile, Noruega e Estados Unidos. Foi um dos relatores do Grupo Executivo da Reforma do Ensino Superior (GERES). Tem escrito seguidamente sobre temas relativos à educação como Ensino Médio, Ensino Superior e Educação Profissional. ${ }^{12}$

Essa presença de intelectuais com grande capital cultural, alguns como assessores ou gestores da educação, e intensa participação internacional trouxe para a Educação Básica e a Educação Superior temáticas que acabariam por se fazerem presentes na elaboração do ordenamento jurídico da educação e nas próprias políticas públicas.

No âmbito da Educação Básica, dois exames ganharam grande dimensão e importância: o Sistema de Avaliação da Educação Básica (SAEB) e o Exame Nacional do Ensino Médio (ENEM). No ensino superior, como já assinalado, instituiu-se o Exame Nacional de Cursos (ENC) ou Provão.

O Provão teve vigência até 2003 e sofreu muitas críticas, seja pelo ranqueamento, seja pelo fato de, examinando os estudantes, avaliar-se a instituição. Dessas críticas e de uma proposição que vinha no projeto de governo de Lula, nasceu outra proposta de avaliação que mantivesse a avaliação externa e, ao mesmo tempo, aferisse outros quesitos de ordem interna e institucional, visando a aspectos referentes à identidade dos estabelecimentos. Trata-se do SINAES, instituído pela Lei n. 10.861/2004. Ela pretende articular os dois paradigmas de avaliação e tê-los, ambos, como complementares entre si.

Mudanças também ocorreram no SAEB, seja por exames por amostragem, seja por exames universais: a Avaliação Nacional da Educação Básica (Aneb) e a Avaliação Nacional do Rendimento Escolar (Anresc) ou Prova Brasil. Posteriormente, os resultados de tais exames, aliados ao Censo Escolar, foram reunidos no Índice de Desenvolvimento da Educação Básica (Ideb), criado em 2007, reu-

\footnotetext{
11 Moura Castro escreve com bastante frequência em revistas semanais do país. Já Batista de Oliveira escreve em jornais de grande circulação.

12 Simon Schwarztmann também passou a fazer parte do NUPES (Núcleo de Pesquisas sobre Ensino Superior) da USP do qual faziam parte José Goldenberg e Eunice Durham.
} 
nindo em um só indicador dois conceitos aferidos para determinar um parâmetro da qualidade da educação: fluxo escolar e médias de desempenho nas avaliações.

Em 1997, no sair da LDB, um artigo de minha autoria sobre a recém-aprovada lei na qual assinalei dois pilares da lei, supra assinalados. Ao analisá-la ponderei que a flexibilidade, se deixada por si, poderia conduzir à precariedade, e a avaliação, a formas homogeneizadoras do processo. Por outro lado, apontava, no texto, os limites que a lei impõe. Ao analisar o pilar da avaliação posta na lei, especialmente os processos de avaliação externava, dizia:

Percebe-se, pois, que a União se investe de poderes sobre a educação escolar em todos os níveis, a partir das noções de coordenação e avaliação como jamais se viu em um regime democrático no Brasil. Ela possui o controle sobre o processo avaliativo do rendimento escolar de todos os níveis da educação escolar e o controle da avaliação das instituições e de cursos do ensino superior, além de baixar normas gerais sobre cursos de graduação e de pós-graduação, de acordo com o inciso VII do art. 9o. A União ganha, pois, a prerrogativa de estabelecer um processo permanente de avaliação do rendimento escolar... (CURY, 1997, p. 105)

Assinalada a importância de uma avaliação, o mesmo texto apontava:

O espírito da lei também parece recusar uma avaliação única, uniforme e centralizada ao insistir em um federalismo cooperativo...Não faz sentido abrir-se para uma flexibilidade processual se depois a avaliação se transformar em uma camisa de força dos sistemas e dos estudantes. (Idem, p. 108)

E o texto finalizava propondo uma avaliação baseada no princípio da gestão democrática: A avaliação flexível, coordenada e cooperativa é aquela em que autoridades e agentes pedagógicos, sob o princípio da cidadania ativa, se congraçam num esforço tal que faça jus ao direito de todos, dever do Estado e da família...com a colaboração da sociedade. (Idem, p. 111)

Essa busca de uma composição entre os dois paradigmas de avaliação da educação perpassa várias estratégias das metas do atual Plano Nacional de Educação. Nele, há várias referências à avaliação em metas (a meta 7 com 36 estratégias) e estratégias (cf. a 7.1 e a 7.4) que permitem afirmar que se busca cumprir o disposto na LDB em seu art. 24, o das regras comuns à Educação Básica, no inciso V, letra a, sobre o rendimento escolar: "avaliação contínua e cumulativa do desempenho do aluno, com prevalência dos aspectos qualitativos sobre os quantitativos e dos resultados ao longo do período sobre os de eventuais provas finais". 
Ou, então, o art. 27 da LDB, que diz:

Os conteúdos curriculares da Educação Básica observarão, ainda, as seguintes diretrizes: [...] I - a difusão dos valores fundamentais ao interesse social, aos direitos e deveres dos cidadãos, de respeito ao bem comum e à ordem democrática; [...] II - consideração das condições de escolaridade dos alunos em cada estabelecimento.

E para tanto há a criação de uma nova arena educacional do regime de cooperação, estabelecida pelo $\ 5^{\circ}$ do art. $7^{\circ}$ da lei n. 13.005/14: a instância permanente de negociação e cooperação entre a União, os Estados, o Distrito Federal e os Municípios. Entre coisas outras, cabe a essa instância que tem como objetivo “pactuar entre União, Estados, Distrito Federal e Municípios.... implantação dos direitos e objetivos de aprendizagem e desenvolvimento que configurarão a base nacional comum curricular ${ }^{13}$ ".

Batemo-nos por um financiamento crescente e vinculado a percentuais de impostos, pela efetivação de um plano nacional de educação e pela titularidade do Estado como certificador de diplomas. Esses e outros documentos públicos da educação teriam o condão de expressar o dever de Estado, sendo que, mais tarde, haveriam de ser os amortecedores de impactos maiores, quando meio mundo passou a postular a saída do Estado da salvaguarda de direitos juridicamente protegidos.

Contudo, o impacto daqueles ventos não sopraria de modo igual e forte por sobre todas as janelas abertas por meio de mobilização e de consagração em sede constitucional. A educação, no Brasil, mercê do financiamento vinculado, do direito público subjetivo, da gratuidade e da obrigatoriedade, da gestão democrática conheceu nesses dispositivos, amortecedores importantes e o impacto trazido pelas orientações e diretrizes dos organismos multilaterais foi diferenciado na educação do que se deu no âmbito da economia. Mas que houve impacto isto é fora de dúvida, especialmente pela avaliação em larga escala mediante testes estandardizados, os quais pelo impacto que geram na mídia, nas instituições, nas famílias e nos próprios estudantes terminam por representar esta avaliação como $a$ avaliação.

\section{CONCLUSÃO}

Em uma democracia, perdem-se espaços em um campo, ganham-se em outro, mas a bússola da educação como direito não perdeu seu sentido, ainda que 
apontando rotas de navegação difícil. Olhando para o mundo capitalismo, tome-se a conclusão da monumental obra de Piketty (2014)

\begin{abstract}
A lição geral de minha pesquisa é que a evolução dinâmica de uma economia de mercado e de propriedade privada, deixada à própria sorte, contém forças de convergência importantes, sobretudo à difusão de conhecimentos e das qualificações, mas também forças de divergência vigorosas e potencialmente ameaçadoras para nossas sociedades democráticas e para os valores de justiça social sobre os quais elas se fundam. (...) O empresário tende inevitavelmente a se transformar em rentista e a dominar cada vez mais aqueles que só possuem sua força de trabalho. Uma vez constituído, o capital se reproduz sozinho, mais rápido do que cresce a produção. $\mathrm{O}$ passado devora o futuro. As consequências podem ser terríveis para a dinâmica de longo prazo da divisão da riqueza, sobretudo se adicionarmos a isso a desigualdade de rendimento em função do tamanho do capital inicial e se esse processo de divergência das desigualdades dos patrimônios se estender à escala mundial. O problema não admite solução simples. O crescimento certamente pode ser estimulado se investir em educação, conhecimento e tecnologias não-poluentes. (p. 555)
\end{abstract}

O princípio da educação, segundo o art. 205 da Constituição, "do pleno desenvolvimento da pessoa", objetivando seu "preparo para o exercício da cidadania e sua qualificação para o trabalho" é direito de todos e dever do Estado.

Por isso, a educação tomada como direito social, direito político e direito civil pela Constituição pede pela explicitação máxima desses direitos e respectivos deveres em uma Lei de Diretrizes e Bases da Educação Nacional, em meados dos anos 90. Dessa Lei consta, inclusive, a defesa de uma formação sólida de profissionais da educação para toda a educação básica em nível superior, com carreira atraente e salários dignos. E, ao fim desses anos, por um Plano Nacional de Educação que fosse um plano real: com diagnóstico, objetivos, metas, meios e recursos financeiros pertinentes às metas.

Os desafios são múltiplos e bastante complexos, além de serem, de algum modo, intercomunicantes. Um Plano, ousado como esse, é uma montagem complexa que corresponde ao enorme aparato institucional da educação escolar brasileira, ai compreendido o federalismo e suas decorrências.

Se esse Plano nasceu de uma perspectiva de que cabe ao Estado junto com a sociedade civil garantir o direito à educação, não podemos esquecer-nos do outro lado da moeda, que é a presença dessa nova racionalidade para o mundo, e de que ela tem papel significativo na imposição de limites a esse direito.

A situação econômico-financeira do país vem conhecendo problemas de natureza variada, inclusive com queda no PIB e no preço do barril do petróleo, o que pode comprometer o alcance das metas e suas estratégias. Como diz Piketty (2014) a respeito de se conhecerem as finanças e a economia, ao concluir seu li- 
vro: "aqueles que possuem muito nunca se esquecem de defender seus interesses. Recusar-se a fazer contas raramente traz benefícios aos mais pobres” (p. 561).

Entretanto há um problema político sério para que o Plano vá adiante. Cabe mais uma vez chamar as vozes de Dardot e Laval (2016) assinalando que o neoliberalismo não é implantado apenas sob a forma chilena sob Pinochet.

\footnotetext{
Convém não confundir estratégia geral com métodos particulares. Estes dependem das circunstâncias locais, das relações de força e das fases históricas: podem tanto empregar a brutalidade do putsch militar como a sedução eleitoreira das classes médias; podem usar e abusar da chantagem do emprego e do crescimento e aproveitar os déficits e as dívidas como pretexto para as "reformas estruturais" como fazem há muito tempo o Fundo Monetário Internacional (FMI) e a União Europeia. O questionamento da democracia toma caminhos diversos, que nem sempre têm a ver com a "terapia de choque", mas, sim, e sobretudo, com o que Wendy Brown chamou, com justiça, de processo de "desdemocratização", que consiste em esvaziar a democracia de sua substância sem a extinguir formalmente. (p. 20) ${ }^{14}$
}

As perspectivas, na dimensão até onde os olhos alcançam, hão de depender das ações já programadas pelo PNE, ai incluídas as avaliações periódicas. E não são poucas. Já as perspectivas, na dimensão da esperança, deixam-nos um sentimento de ambiguidade. As experiências passadas pouco recomendáveis de um PNE, a complexidade do PNE e a atual conjuntura político-econômica, de um lado, e, de outro, movimento para montá-lo, apontam para o 'pessimismo do intelecto' e o 'otimismo da vontade'.

\section{REFERÊNCIAS}

ALMEIDA, Ana Maria F. O assalto à educação pelos economistas. Tempo social, São Paulo, v. 20, n. 1, 2008.

ALMEIDA, Ana Maria F. Le langage autorisé pour penser Le système educatif: les économistes à la conquête de nouveaux pouvoirs. Cahiers de La Recherche sur l'Éducation et les Savoirs, v.2, p.117-137, 2009.

BAUMAN, Zygmunt. Vidas desperdiçadas. Trad. Carlos Alberto Medeiros. Rio de Janeiro: Jorge Zahar, 2005. 
BERGOGLIO, Jorge Mario - Papa Francisco. (2015) Laudato Si, mi Signore. http://w2.vatican.va/content/francesco/pt/encyclicals/documents/papa-francesco_20150524_enciclica-laudato-si.html, consulta em 13/06/2016.

BOBBIO, Norberto. A Era dos Direitos. Rio de Janeiro: Campus, 1992.

BOVERO, Michelangelo. Crepúsculo de la democracía? In: BOVERO, Michelangelo e PAZÉ, Valentina. La democracia en nueve lecciones. Madrid: Editorial Trotta, 2014.

CURY, Carlos Roberto Jamil. A nova lei de Diretrizes e Bases da Educação Nacional: uma reforma educacional? In: CURY, Carlos Roberto Jamil; HORTA, José Silvério Bahia e BRITO, Vera Lúcia Alves de (orgs.). Medo à Liberdade e Compromisso Democrático: LDB e Plano Nacional da Educação. São Paulo: Editora do Brasil, 1997.

DARDOT, Pierre e LAVAL, Christian. A nova razão do mundo: ensaio sobre a sociedade neoliberal. São Paulo: Boitempo, 2016.

DRAIBE, Sônia. As políticas sociais e o neoliberalismo. Revista USP, n. 17, março/abril/maio, pgs. 86-101, 1993.

LAVAL, Christian. A Escola não é uma empresa: o neo-liberalismo em ataque ao ensino público. Londrina: Planta, 2004.

MCGANN, James. Global Go To Think tanks. Index Report. Philadelphia: University of Pennsylvania, 2013. Disponíveis http://repository.upenn.edu/cgi/ viewcontent.cgi?article $=1009 \&$ context $=$ think_tanks. Acesso em 09/09/2016

MELO, Hivy Damásio Araújo. O Banco Mundial e a Educação no Brasil: convergências em torno de uma agenda global. 2012. Tese (Doutorado em Sociologia) - Universidade Estadual de Campinas, Campinas, 2012.

MEYER, Hans-Dieter. The OECD as Pivot of the Emerging Global Educational Accountability Regime: how accountable are the accountants? Teachers College Record, the Voice of Scholarship in Education. Volume 116 Number 9, p. 1-20, 2014b. http://www.tcrecord.org ID Number: 17543, Date Accessed: 6/14/2016 8:44:14 AM 
MEYER, Hans-Dieter, TRÖHLER, Daniel, LABAREE, David F and HUTT, Ethan. Accountability: antecedents, power and process. Teachers College Record, the Voice of Scholarship in Education. Volume 116, number 9, p. 1-12, 2014b. http:/ /www.tcrecord.org ID Number: 17543, Date Accessed: 6/14/2016 9:57:14 AM

MORENO, Rosangela Carrilo. ONGS com mandato para elaborar políticas públicas? A participação de ONGS nas políticas de alfabetização e de ensino de jovens e de adultos no Brasil (1990-2010). 2016. 274p. Tese (Doutorado em Educação) - Universidade Estadual de Campinas (UNICAMP), Campinas, 2016.

PIKETTY, Thomas. O Capital no século XXI. Rio de Janeiro: Intrínseca, 2014.

RUANO-BORBALAN, Jean-Claude. Globalização. In: VAN ZANTEN, Agnés (coord.) Dicionário de Educação. Petrópolis: Vozes, 2011.

SAVIANI, Dermeval. A nova lei da educação: trajetória, limites e perspectivas. $11^{\mathrm{a}}$ ed., Campinas: Autores Associados, 2008

SCHNEIDER, Marilda Pasqual. Políticas de Avaliação em larga escala e a construção de um currículo nacional para a educação básica. EccoS - Revista Científica, São Paulo, n. 30, jan/abril, p. 17-33, 2013

SOUZA, Paulo Renato de. A Revolução Gerenciada: educação no Brasil, 19952002. São Paulo: Prentice Hall, 2005.

WERLE, Flávia Obino Corrêa. Panorama das políticas públicas na educação brasileira: uma análise das avaliações externas dos sistemas de ensino. Revista Lusófona de Educação, Lisboa, n. 27, set, p. 159-179, 2014.

CARLOS ROBERTO JAMIL CURY possui graduação em Filosofia pela Faculdade de Filosofia Ciências e Letras Nossa Senhora Medianeira (1971), mestrado em Educação: História, Política, Sociedade pela Pontifícia Universidade Católica de São Paulo (1977) e doutorado em Educação: História, Política, Sociedade pela Pontifícia Universidade Católica de São Paulo (1979). Fez seu pós-doutorado, em 1994, junto à Faculdade de Direito do Largo S.Francisco-USP. A seguir, agora junto à Université de Paris (René Descartes, em 1995, continuou seus estudos pós-doutorais. Entre 
1998-1999 fez outros estudos de pós-doutorado na École des Hauts Études en Sciences Sociales, EHESS, França. Em 2011 fez um estágio pós doutoral na UFRJ. É professor titular (aposentado) da Faculdade de Educação da UFMG, da qual é professor emérito. É professor adjunto da Pontifícia Universidade Católica de Minas Gerais atuando na Graduação e Pós-Graduação (mestrado e doutorado). E-mail: crjcury.bh@terra.com.br

Recebido em novembro de 2016 Aprovado em dezembro de 2016 